Research Article

Xue Haitao, Wang Dengke, and Song Kaihong*

\title{
Effect of deformation temperature on mechanical properties and microstructure of TWIP steel for expansion tube
}

https://doi.org/10.1515/htmp-2020-0020

Received Sep 06, 2019; accepted Nov 23, 2019

\begin{abstract}
According to the downhole temperature filed, the mechanical behavior of TWIP steel for expansion tube was studied in the temperature range from $25^{\circ} \mathrm{C}$ to $300^{\circ} \mathrm{C}$. Meanwhile, the phase and microstructure changes before and after deformation were investigated by X-ray diffractometer (XRD), optical microscope (OM), scanning electron microscopy (SEM) and transmission electron microscopy (TEM). The results indicate that yield strength, tensile strength and elongation decrease with temperature increasing. The TWIP steel is single-phase of austenite before and after deformation. Analysis on the microstructure shows that the deformation twins gradually decrease with increasing temperature. The deformation process cannot benefit from the deformation twins, which is responsible for the decreased ductility. In addition, due to the increased temperature, the stacking fault energy becomes high enough to restrain twinning, thus dislocation glide becomes the main deformation mechanism.
\end{abstract}

Keywords: TWIP steel; deformation temperature; mechanical property; deformation twins

\section{Introduction}

Expandable tubular technology is an important emerging technology in the field of drilling [1], and the properties of expansion tube materials restrict the development of expandable tube technology. In order to adapt to the development of oil and natural gas industry, it is very meaningful to develop new type steels with high strength and plasticity and corrosion resistance to be expansion tube

\footnotetext{
${ }^{\star}$ Corresponding Author: Song Kaihong: School of materials sci-
ence and engineering, Hebei University of Technology, Tianjin,

^Corresponding Author: Song Kaihong: School of materials sci
ence and engineering, Hebei University of Technology, Tianjin, China; Email: Kevin_skh@126.com

Xue Haitao, Wang Dengke: School of materials science and engineering, Hebei University of Technology, Tianjin, China
}

əopen Access. (c) 2020 X. Haitao et al., published by De Gruyter. (cc) BY License materials [2], especially in the downhole temperature filed. Grassel et al. [3, 4] discovered TWIP steel when studying Fe-Mn-Si-Al TRIP steel and proposed the concept of TWIP, namely twin-induced plastic steel. The new type of TWIP steel with stable austenitic structure at room temperature has high elasticity, strength, elongation, good cryogenic property and strain hardening performance, which has attracted great attention in automotive, petroleum and other high-tech fields at home and abroad [5-8].

As for the materials of expansion tube, foreign countries mostly adopt 316L stainless steel, which can basically meet the technical requirements when used in shallow oil and gas Wells, but has potential safety risks for deep oil and gas wells (2000-4000m) and ultra-deep wells (4000$10000 \mathrm{~m}$ ) [9]. Therefore, it is one of the important tasks to explore the better performing steel as expansion tube steel. In recent years, Sheng li Oil Field drilling institute has carried on the beneficial exploration to the optimization of tubular materials. For N80 and P110 casings, their poor plasticity and fluidity lead to the result of cracks in the process of expansion. The low expansion rate of J55 and K55 casings make it unable to complete the expansion process normally. In this context, TWIP steel with high plasticity and strength emerged, and its deformation mechanism is that dislocation motion is hindered by interstitial atom and grain boundary with low strain [10], then twinning is the main deformation mechanism and hardening mechanism, so the formation of deformation twins accumulate a certain amount of pre-strain [11-13]. Hu et al. [14] pointed out that the internal structures of TWIP steel presented successively with the increase of deformation were as follows: a large number of dislocations, twins and intersecting multiple twin systems, which equipped TWIP steel with high work-hardening capacity and elongation in mechanical properties. Yang et al. [15] found that TWIP steel still maintained high strength and elongation at different temperatures and had good comprehensive mechanical properties.

TWIP steel is used to prepare expandable tube, which can not only improve the performance of expandable tube, 
Table 1: The tensile mechanical properties of TWIP steel at different deformation temperatures

\begin{tabular}{ccccc}
\hline Temperature ${ }^{\circ} \mathrm{C}$ & Yield strength (MPa) & Tensile strength (MPa) & Elongation (\%) & strength-ductility (MPa\%) \\
\hline 25 & 404.81 & 810.17 & 64.62 & 52353.19 \\
100 & 370.00 & 713.85 & 58.85 & 42010.07 \\
200 & 341.20 & 632.65 & 48.94 & 30961.89 \\
300 & 272.96 & 562.94 & 46.27 & 26047.23 \\
\hline
\end{tabular}

enhance the safety of work and expand the application range, but also bring a competitive advantage in expansion tube industry and save the cost. Therefore, TWIP has good economic and social benefits and broad prospects of development.

\section{Materials and methods}

The main chemical composition (wt- $\%$ ) of experimental TWIP steel was: $0.21 \mathrm{C}$; $25 \mathrm{Mn}$; $0.9 \mathrm{Si}$; $1.8 \mathrm{Al}$; Fe rest. Seamless steel tube with the dimensions of $219 \times 18 \mathrm{~mm}$ was prepared by hot extrusion. After hot extrusion, the TWIP tube was treated with solution treatments at $1050^{\circ} \mathrm{C}$ for $15 \mathrm{~min}$. Tensile specimens were wire cut along the TWIP tube axial direction. The specimens were prepared based on GBT/228.22015 standard with a gauge length of $120 \mathrm{~mm}$, gauge width of $4 \mathrm{~mm}$ and thickness of $2 \mathrm{~mm}$, but the grip sections of tensile specimens were modified to be wider than the standard grip area to prevent any sliding during the tensile experiment. Tensile tests were performed on the highlow temperature tensile testing machine. The test temperatures were $25^{\circ} \mathrm{C}, 100^{\circ} \mathrm{C}, 200^{\circ} \mathrm{C}$, and $300^{\circ} \mathrm{C}$ with its error at $\pm 2^{\circ} \mathrm{C}$, and the nominal strain rate was $1 \times 10^{-3} \mathrm{~s}^{-1}$.

After tensile testing, specimens used for microstructure characterization were cut near the fracture. The specimens were mechanically polished and then corroded by alcohol solution containing $4 \%$ of nitric acid (volume fraction).

The phase identification of the samples after fracture was conducted by X-ray diffractometer (XRD) with scanning speed and range of $6^{\circ} / \mathrm{min}$ and $0^{\circ}-90^{\circ}$, respectively. Optical microscope (OM), scanning electron microscope (SEM) and transmission electron microscopy (TEM) were used to observe microstructure of tensile specimens after fracture. The tensile fracture morphology was also observed by SEM.

\section{Results and analyses}

\subsection{Tensile behavior of TWIP steel at the temperature range from $25^{\circ} \mathrm{C}$ to $350^{\circ} \mathrm{C}$}

According to the working conditions of oil and gas fields, the tensile tests were conducted at $25^{\circ} \mathrm{C}, 100^{\circ} \mathrm{C}, 200^{\circ} \mathrm{C}$ and $300^{\circ} \mathrm{C}$. The experiments were performed at a nominal strain rate of $1 \times 10^{-3} \mathrm{~s}^{-1}$. Stress-strain curves of TWIP steel at different temperatures and their partial enlargement drawings are showed in Figure 1.

The curves in Figure 1 clearly show decreasing yield strength, tensile strength, elongation and Strengthductility (see Table 1) of the specimens at different temperatures. The results in Table 1 are are consistent with those reported by V. Shterner et al. [16].

The ultimate tensile strength occurred at a strain level close to fracture. Therefore, the uniform elongation was close to the total elongation, showing that the deformation was mostly uniform. Discontinuous yielding in the form of serrations on the stress-strain curves is observed at the temperature of $100^{\circ} \mathrm{C}, 200^{\circ} \mathrm{C}, 300^{\circ} \mathrm{C}$, but is pronounced at $300^{\circ} \mathrm{C}$. Serration starts at a strain of 0.04 until the specimen fractured at $300^{\circ} \mathrm{C}$. For tensile samples at $100^{\circ} \mathrm{C}$ and $200^{\circ} \mathrm{C}$, stress-strain curves are smooth in the early phase the deformation, then serrations become obvious as the deformation developed. Existing studies have proved that these serrations were interpreted as a footprint of dynamic strain aging (DSA) which was caused by the interaction between dislocation motion and atoms diffusion [17]. Dynamic strain aging appeared at a certain amount of the plastic deformation, and the higher test temperature was, the more obvious serrated appearance became [18-20].

Yield strength $(\mathrm{Rm})$, tensile strength (ReL), elongation (A) and strength-ductility (k) obtained by tensile tests at diffferent temperatures are shown in Table 1. Figure 2 shows the change trend of main mechanical performance indexes. It can be seen from Figure 2 and Table 1 that the yield strength, tensile strength and elongation of TWIP steel decrease as the temperature increases. The tensile strength has a $30.5 \%$ drop from $810.17 \mathrm{MPa}$ at $25^{\circ} \mathrm{C}$ to 562.94 

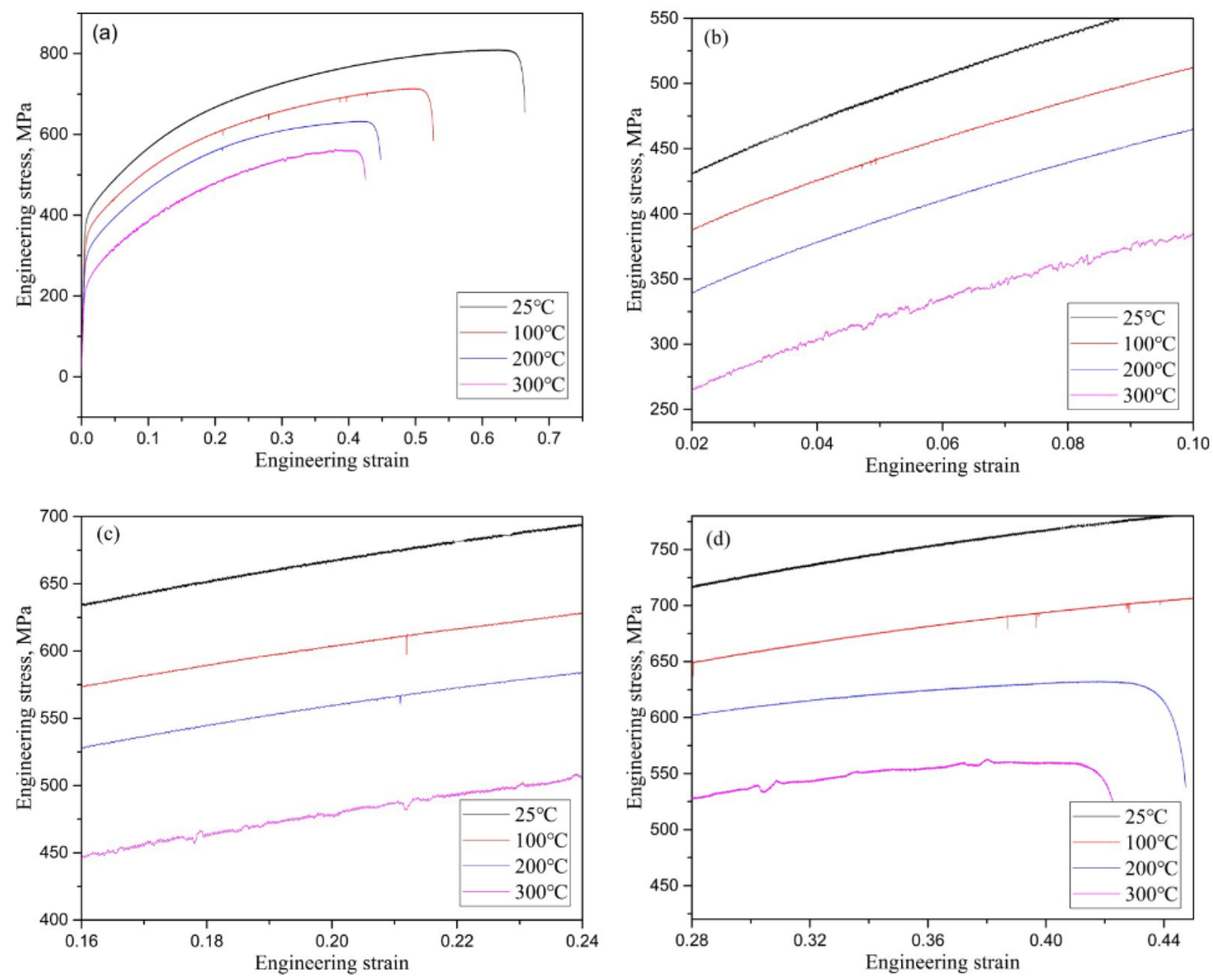

Figure 1: The stress-strain curves (a) and the magnified sections (b), (c), (d) at different tensile testing temperatures

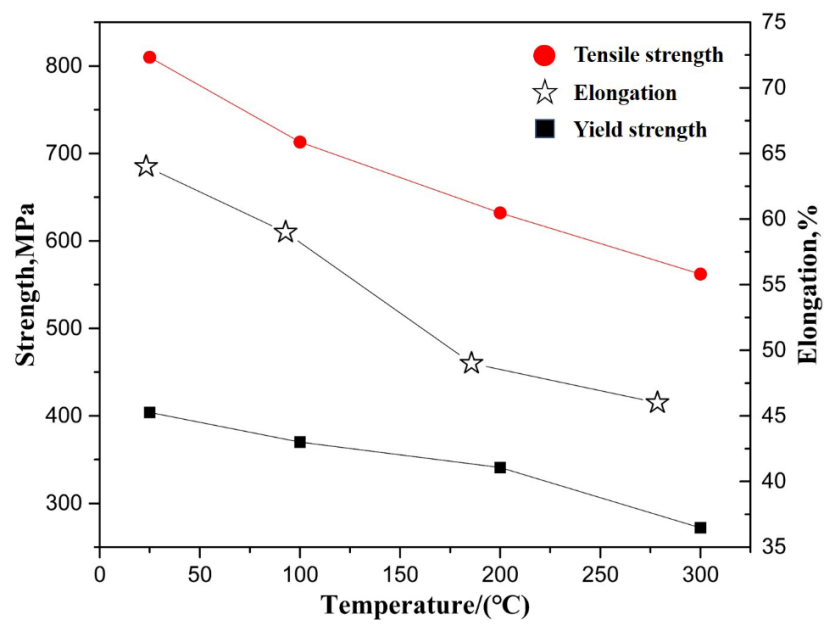

Figure 2: Mechanical performance curves
$\mathrm{MPa}$ at $300^{\circ} \mathrm{C}$. Also, the elongation decreases by $28.4 \%$ from $64.62 \%$ to $46.27 \%$.

For the study of TWIP steel's work-hardening behavior, the Strain hardening exponent (n) is an important index to characterize the work-hardening behavior of materials. The value of $\mathrm{n}$ reflects the ability of materials to resist even deformation before necking. Log-log plot curve is obtained by taking log of the true stress-true strain, and use the curve fit for the entire strain hardening portion of the curve (until the load maximum). Figure 3 indicates that every log-log plot is sunken, and the strain hardening exponent (n) drops and then increases with the increase of temperature. The $n$-values in Figure 4 are slope of linear fitting curves which indicate that $\mathrm{n}$-value decreases and then increases. 

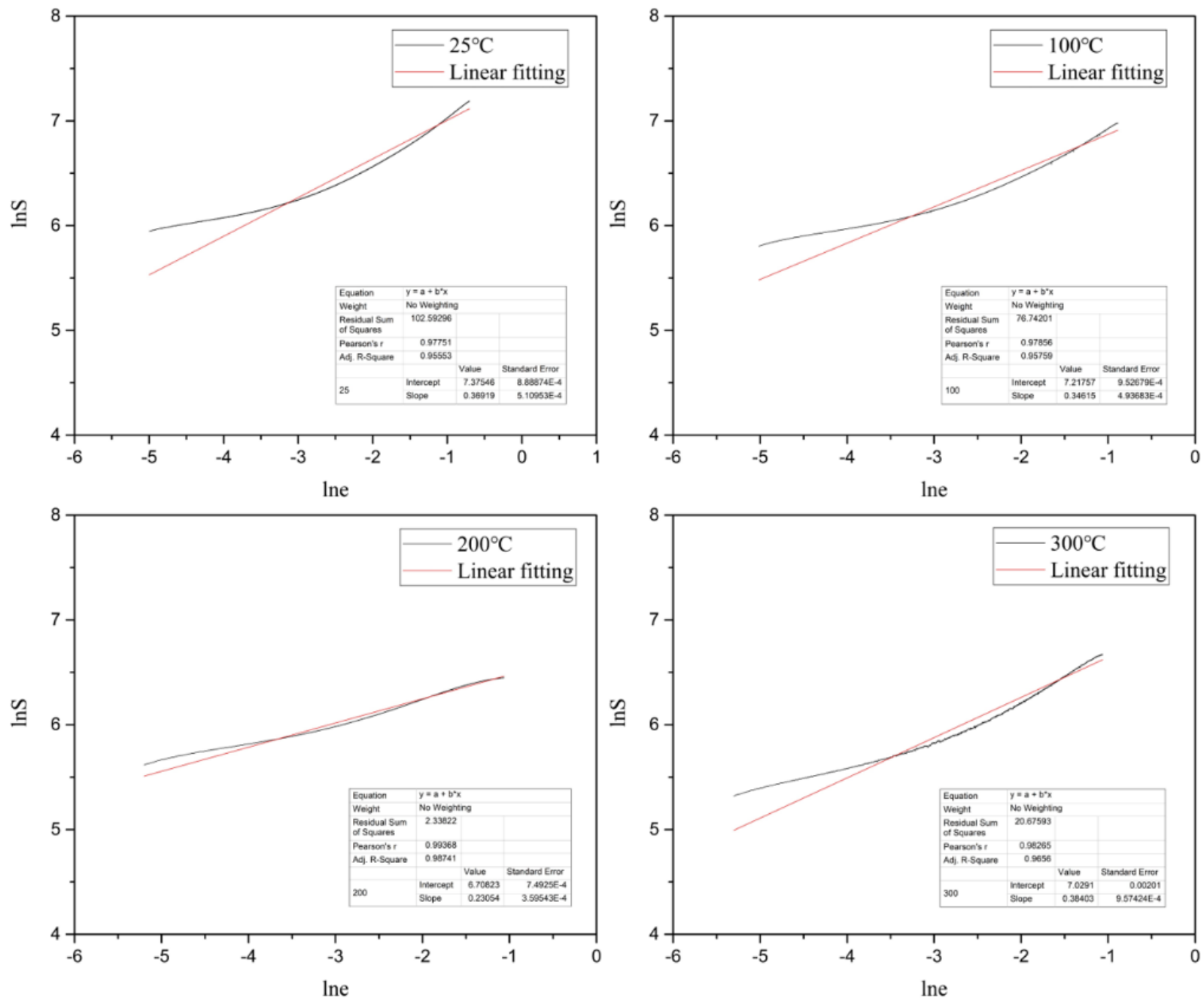

Figure 3: InS-Ine curves of TWIP steel at $25^{\circ} \mathrm{C}, 100^{\circ} \mathrm{C}, 200^{\circ} \mathrm{C}$ and $300^{\circ} \mathrm{C}$

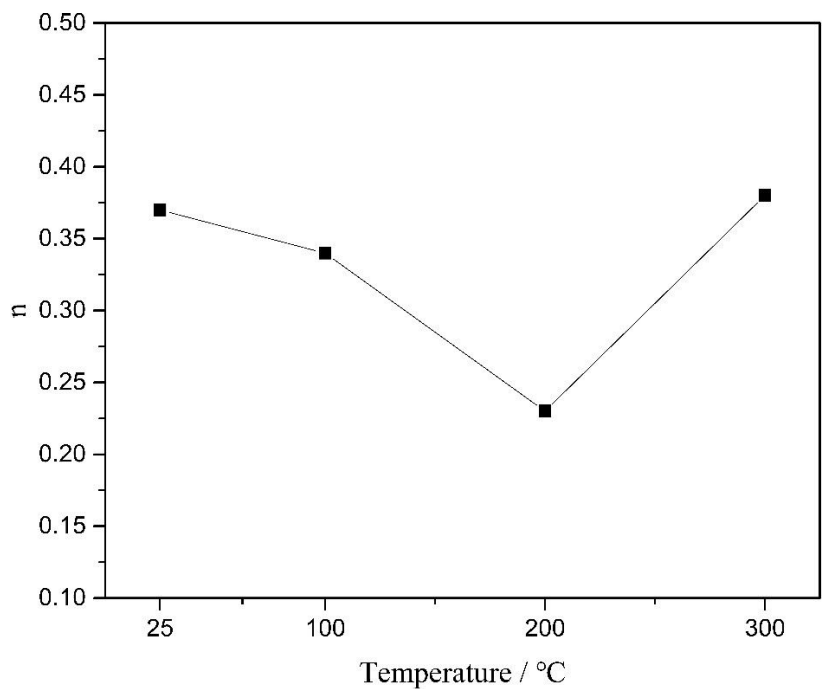

Figure 4: Strain hardening exponent (n) at different temperatures

\subsection{Microstructure and morphology}

\subsubsection{XRD analysis of TWIP steel at different deformation temperatures}

Figure 5 shows the XRD pattern of the base metal and specimens after fracture at different temperatures. It is obvious that the specimens retain a single austenite phase before and after deformation.

The results above indicated that the TWIP steel didn't produce deformation-induced martensite during the process of tensile tests at experimental temperature range of $25-300^{\circ} \mathrm{C}$. Given the strength of the diffraction peak, the peak (111) intensity of the three samples after tensile test reduces obviously, but the intensity of peak (220) becomes stronger. Changes in the intensity of the diffraction peak indicate that the orientation of crystal changes in order to coordinate deformation. The analysis shows that $\{112\}<111>$ 


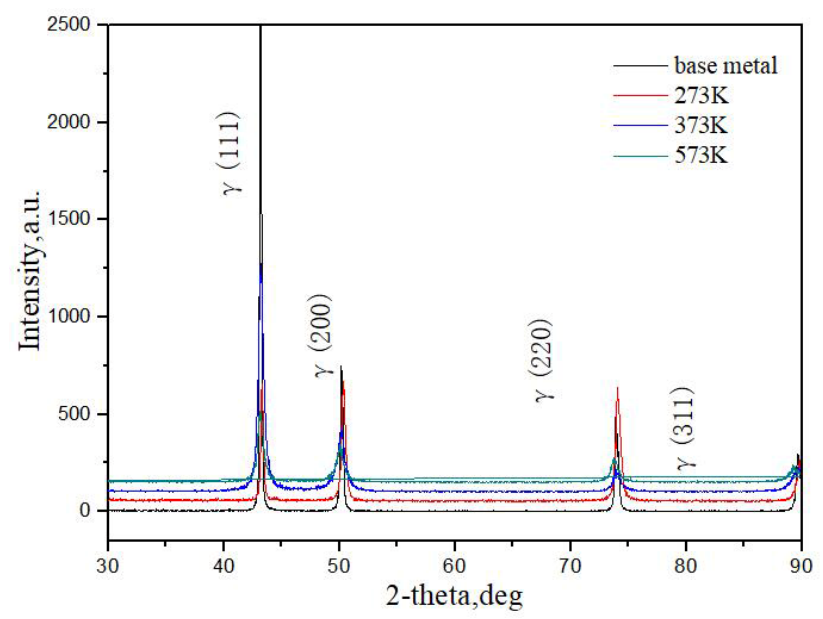

Figure 5: XRD diagram of TWIP steel at different deformation temperatures

texture [21] is formed along the stretching direction during the tensile process. The strength of texture formation is related to the temperature of dynamic tensile, and the trend is that the formation of texture is weakened with the increase of dynamic tensile temperature because the increasing deformation temperature raises the SFE, which decreases the twinning rate and drawability of TWIP steel [4]. Benzing et al. [22] showed that the heat built up in the tensile specimen and stabilized the austenite by increasing the SFE during the deformation.

\subsubsection{Microstructure analysis of TWIP steel after tensile}

The initial microstructure of TWIP steel is single-phase of austenite with a small number of annealing twins distributed in the matrix. The microstructure of the specimens tested by conventional tensile test until fracture are showed in Figure 6.

Figure 6a shows that all grains with the preferred orientations contain high density of deformation twins which separate grains, and contribute to the "grain refinement" effect. At the same time, deformation twins contribute to even plastic deformation of TWIP steel, because it can change the grain orientation which promote the slip of dislocation. At $300^{\circ} \mathrm{C}$, the amount of twins after fracture drops drastically (see Table 2) from $55.32 \%$ to $18.30 \%$ which is related to the stacking fault energy. With temperature increasing, the critical stress needed to initiate twinning may have increased due to the increased stacking fault energy. Therefore, fewer deformation twins are observed at the deformation temperatures of $200^{\circ} \mathrm{C}$ and $300^{\circ} \mathrm{C}$.
Deformation twinning can lead to higher strain hardening rate and delay necking $[23,24]$. The observation suggests that the decreased number of deformation twins cannot maintain the high level of elongation as in the case of the room temperature deformation. Therefore, the deformation process cannot benefit from the twins that much and the specimen will fail earlier at elevated temperature. Further increasing the test temperature to $300^{\circ} \mathrm{C}$, deformation twinning entirely disappears. Due to the increased temperature, the stacking fault energy becomes high enough to restrain twinning, thus dislocation glide will become the main deformation mechanism [20]. This suggests that the critical strain for deformation twinning increases with an increase in the tensile testing temperature.

Based on the SEM images of specimens, large differences can be observed at different temperature, as it is detailed on Figure 7. The characteristics of the twins is also clearly shown in the SEM images. Figure $7 \mathrm{a}$ is the original solid-solution state of austenitic matrix distributed the annealing twins which were shaped like groove [25]. Figure $7 \mathrm{~b}$ indicates that a large number of deformation twins are produced after tensile test at room temperature which is significantly different from original structure. The twins shaped like groove become finer and intercrossed, which indicates that secondary twins are formed and refine grains during the deformation process. At $100^{\circ} \mathrm{C}$ and $300^{\circ} \mathrm{C}$, the differences in microstructure seem very slight, compared with the original structure. The results indicate that slip mechanism becomes a main deformation mechanism with the deformation twins gradually disappearing due to the increase of testing temperature.

Quantitative metallography is used to analyze the twins in the SEM images of tensile specimens at different temperatures. Thirty different regions in every specimen are selected to observe and calculate the twin speckle and determine the proportion of twins. The metallographic images are messed by Photoshop, with each panel being $10^{\star} 10$ pixels in size. The number of intersection points between twin zone and grid is denoted as PP. The calculation method adopted is as follow: if the grid intersection point is inside the twin area, the PP value is 1 ; if the grid intersection point is at the boundary of the twin area, the PP value was 0.5 , and the total number of grid intersection points is PT in the image. The proportion of twins $\left(\mathrm{A}_{T}\right)$ is given by:

$$
A_{T}=\frac{P P}{P T}
$$

The calculation results are shown in Table 2. It is obvious that the proportion of twins $\left(\mathrm{A}_{T}\right)$ is seen to continuously decrease when temperature rises from room temperature 

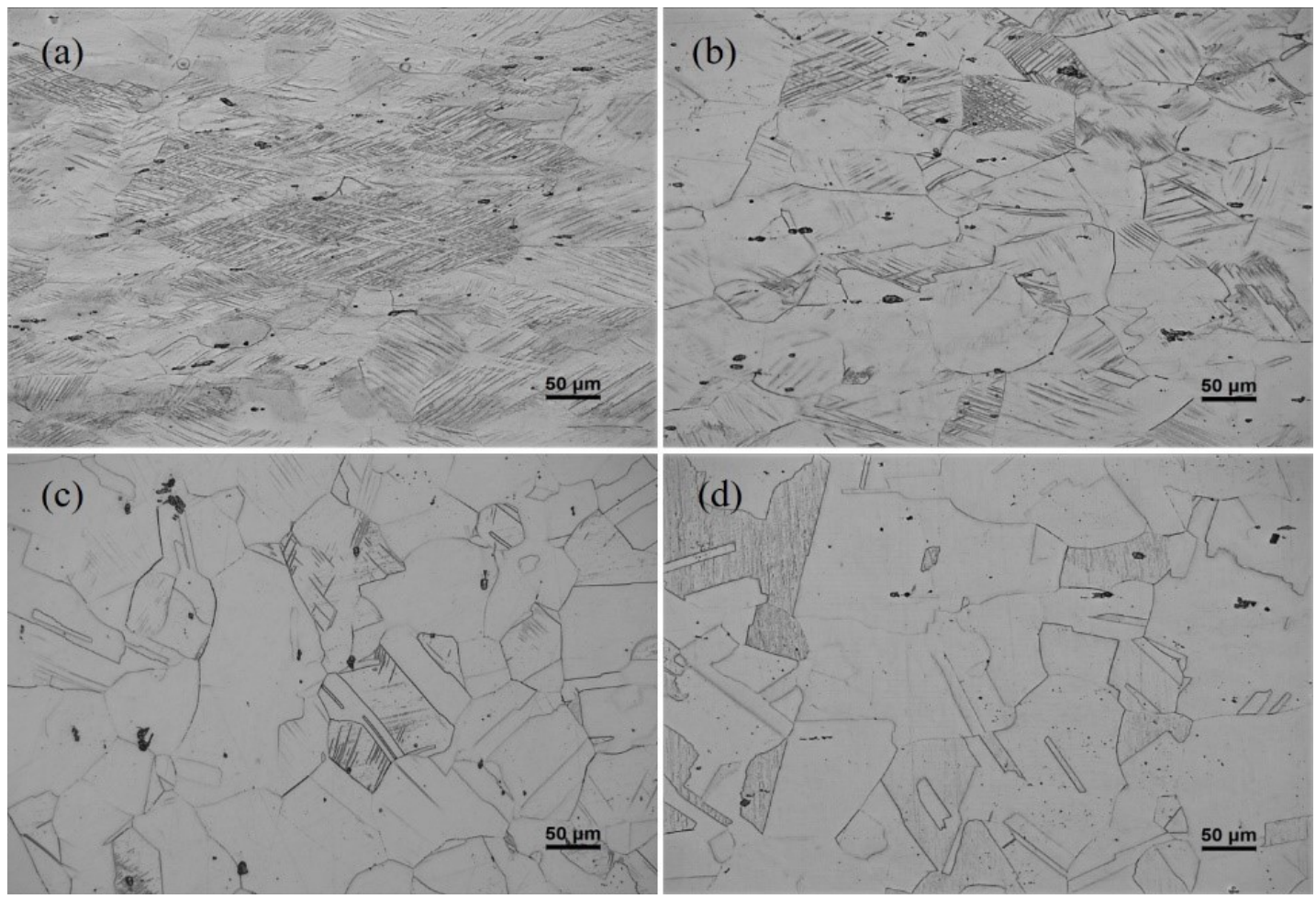

Figure 6: Grain morphology of TWIP steel. (a) $25^{\circ} \mathrm{C}$, (b) $100^{\circ} \mathrm{C}$, (c) $200^{\circ} \mathrm{C}$, (d) $300^{\circ} \mathrm{C}$
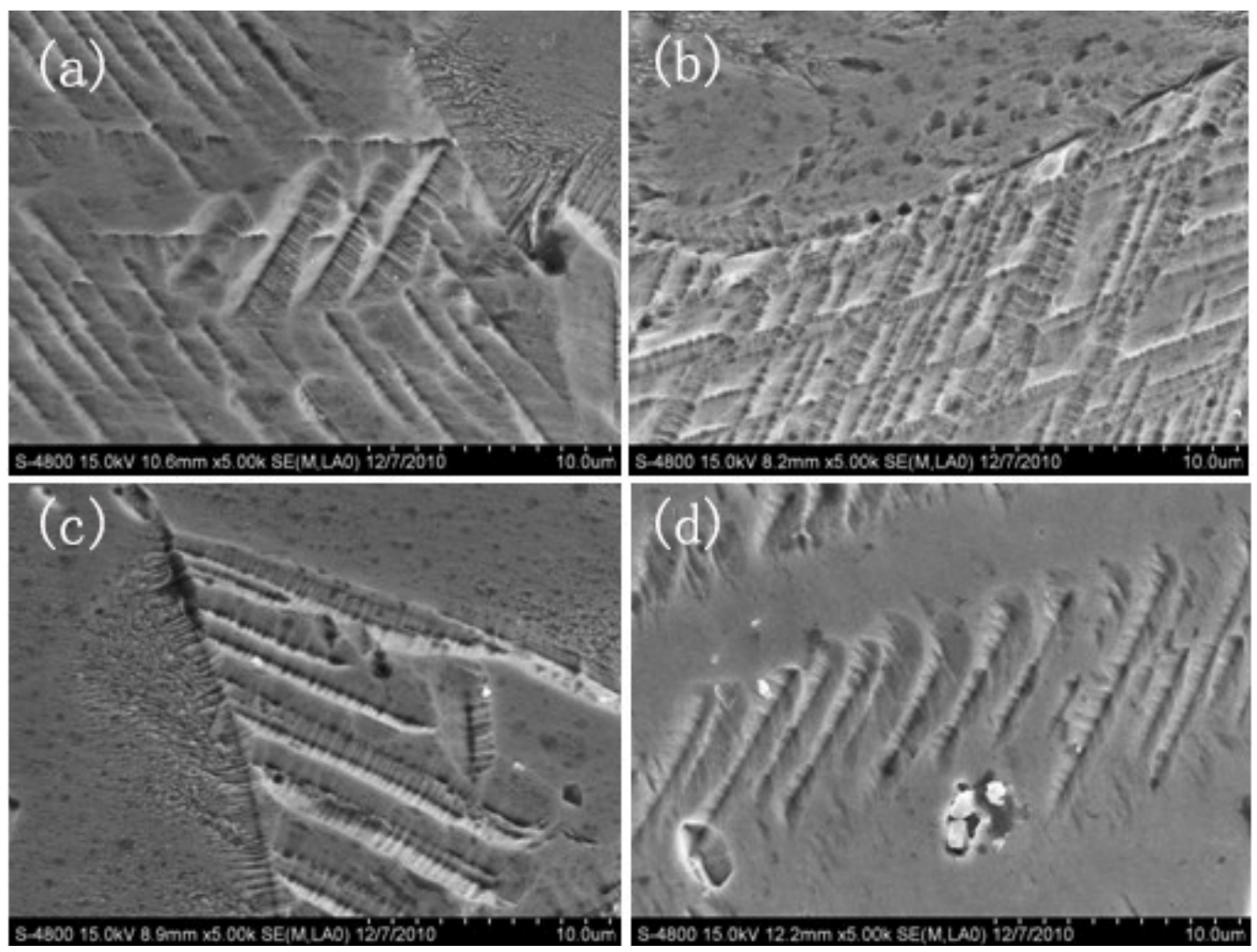

Figure 7: The SEM photographs of TWIP steel (a) base metal, (b) $25^{\circ} \mathrm{C}$, (c) $100^{\circ} \mathrm{C}$, (d) $300^{\circ} \mathrm{C}$. 


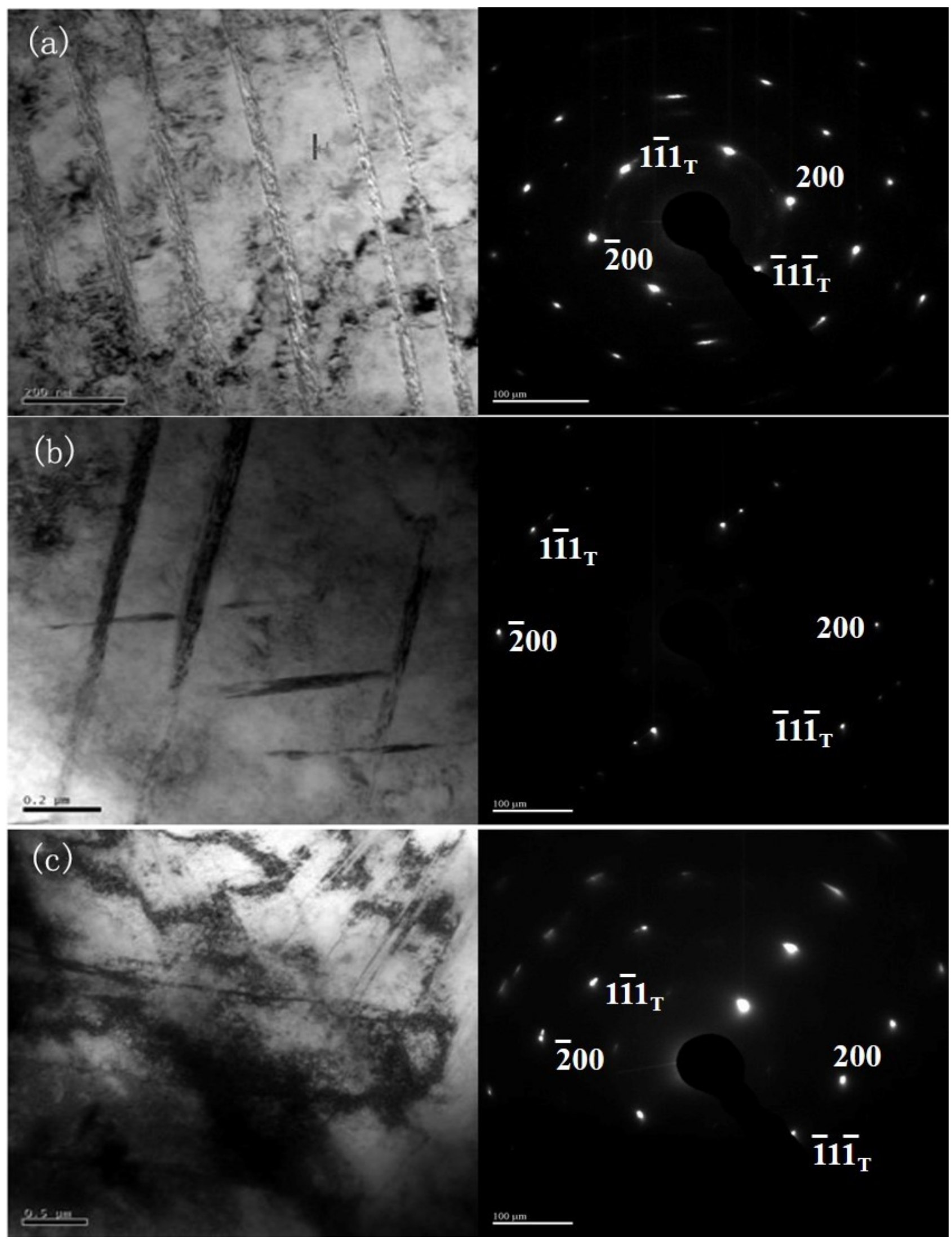

Figure 8: TEM morphology of samples after fracture: (a) $25^{\circ} \mathrm{C}$, (b) $100^{\circ} \mathrm{C}$, (c) $300^{\circ} \mathrm{C}$ 


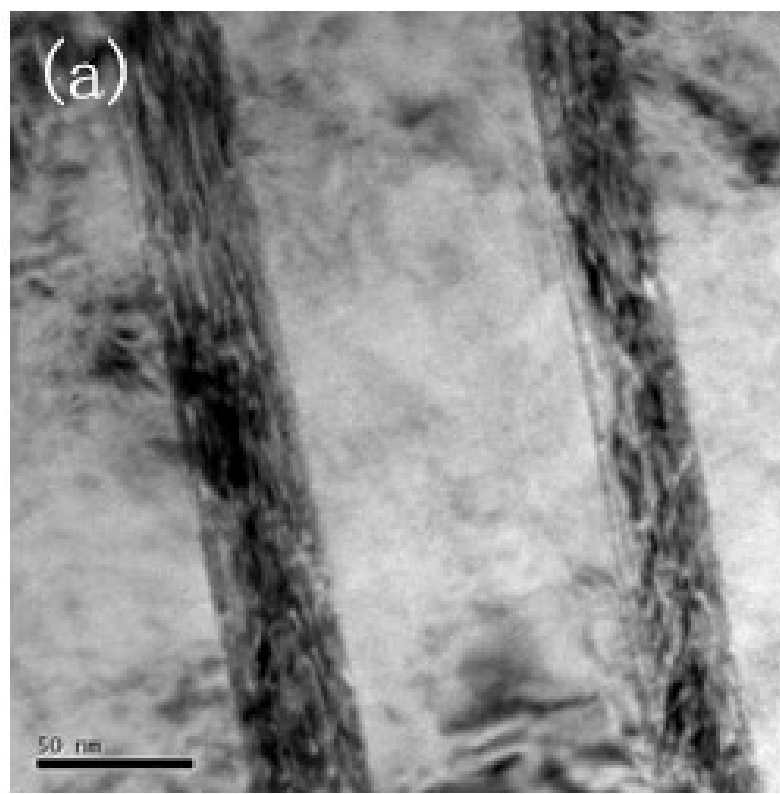

Figure 9: TEM image of twin structure (a) $25^{\circ} \mathrm{C}$, (b) $100^{\circ} \mathrm{C}$

Table 2: Proportion of twins at different deformation temperatures

\begin{tabular}{ccccc}
\hline Temperature & $25^{\circ} \mathrm{C}$ & $100^{\circ} \mathrm{C}$ & $200^{\circ} \mathrm{C}$ & $300^{\circ} \mathrm{C}$ \\
\hline $\mathrm{A}_{T}(\%)$ & 55.32 & 18.30 & 9.63 & 1.94 \\
\hline
\end{tabular}

to $300^{\circ} \mathrm{C}$. There is a significant drop at $100^{\circ} \mathrm{C}$, and the proportion of twins is only $1.94 \%$ at $300^{\circ} \mathrm{C}$.

Figure 8 is the TEM image of the samples after fracture at different deformation temperature. The results obtained by TEM were consistent with those by SEM. Figure $8 \mathrm{a}$ indicate that there are high amounts of twins in the specimen after fracture at $25^{\circ} \mathrm{C}$. As shown in Figure $8 \mathrm{~b}$ and $8 \mathrm{c}$, the deformation twins decrease with the increase of temperature, and twins are rarely found in the deformation temperature of $300^{\circ} \mathrm{C}$. While, a mass of dislocation can be clearly observed at $300^{\circ} \mathrm{C}$, which is related to the increase of stacking fault energy (SFE).

It can be seen from Table 2 that the amounts of deformation twins decrease with the increase of tensile temperature. When the temperature reaches $300^{\circ} \mathrm{C}$, deformation twin barely exists. As the number of twins decreases, the strength and ductility of TWIP steel are reduced. The analysis indicates that there exists a certain temperature range which is responsible for the change of deformation mechanism. Deformation twins produced at room temperature account for about $55 \%$, fell to $18 \%$ at $100^{\circ} \mathrm{C}$ and are barely found at $300^{\circ} \mathrm{C}$. Therefore, the deformation mechanism of TWIP steel changes before $100^{\circ} \mathrm{C}$. That is to say, the

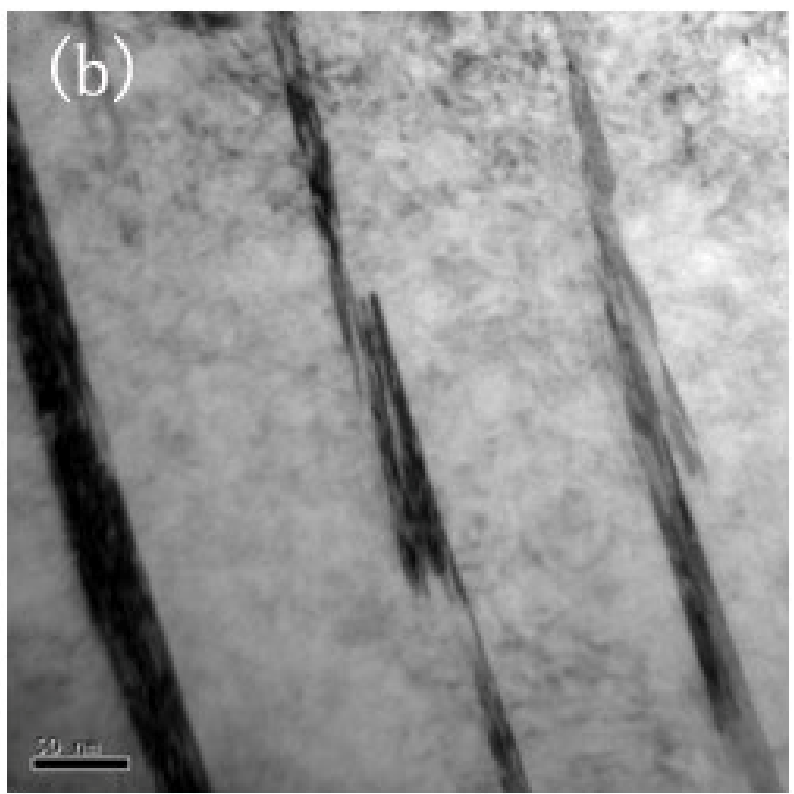

transformation of deformation mechanism of TWIP steel occurred in the temperature range from $25^{\circ} \mathrm{C}$ to $100^{\circ} \mathrm{C}$.

Testing temperature not only affects the change of deformation mechanism, but also affects the shape and internal structure of deformation twins. Figure 9 is the twin structure of the specimens at $25^{\circ} \mathrm{C}, 100^{\circ} \mathrm{C}$. It can be seen that the deformation twins with size of about $30-40 \mathrm{~nm}$ generated at room temperature, and the spacing between deformation twins is about $100 \mathrm{~nm}$. At $100^{\circ} \mathrm{C}$, the spacing of the deformation twins have not change, but the width of the deformation twins become narrowed down to 20-30 $\mathrm{nm}$. Moreover, the twin planes change and the cross-slip of dislocation appears with the temperature rising. The twins may be generated and grow in the adjacent slip plane. Through TEM images, it is found that deformation twins with an angle of about 110 degrees are generated at $100^{\circ} \mathrm{C}$. At room temperature, the boundary of deformation twin, which is straight and smooth and filled with dislocation. At $100^{\circ} \mathrm{C}$, a large number of dislocations accumulate in the twin boundary, which become fuzzy and irregular.

\subsubsection{Morphology of tensile fracture surface of TWIP steel}

Tensile tests of TWIP steel were carried out at the speed of $1 \mathrm{~mm} / \mathrm{min}$ under different temperature conditions. By using SEM, tensile fracture morphology is observed, as shown in Figure 10 and Figure 11. 

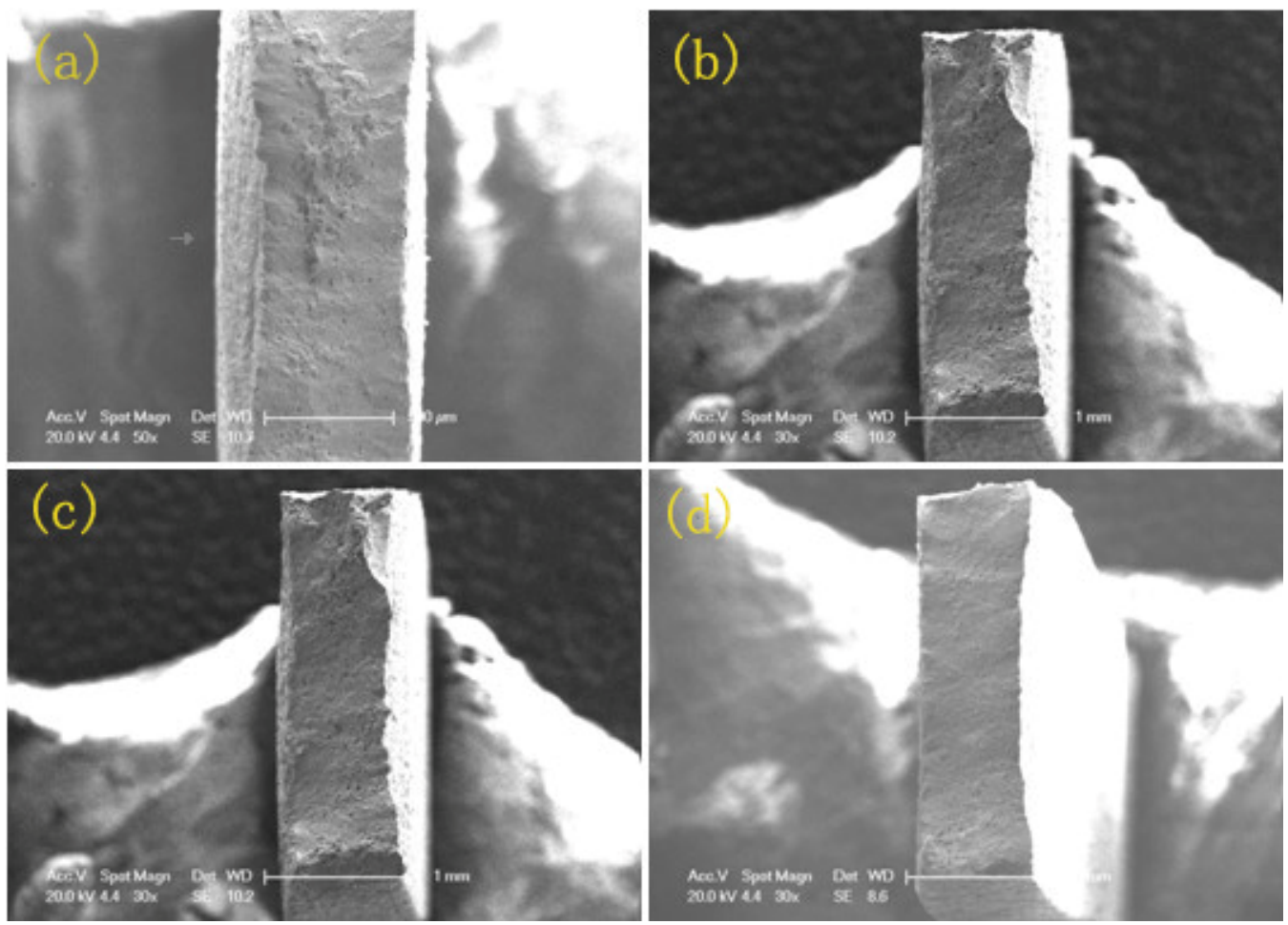

Figure 10: Fracture morphology a) $25^{\circ} \mathrm{C}$, b) $100^{\circ} \mathrm{C}$, c) $200^{\circ} \mathrm{C}$, d) $300^{\circ} \mathrm{C}$
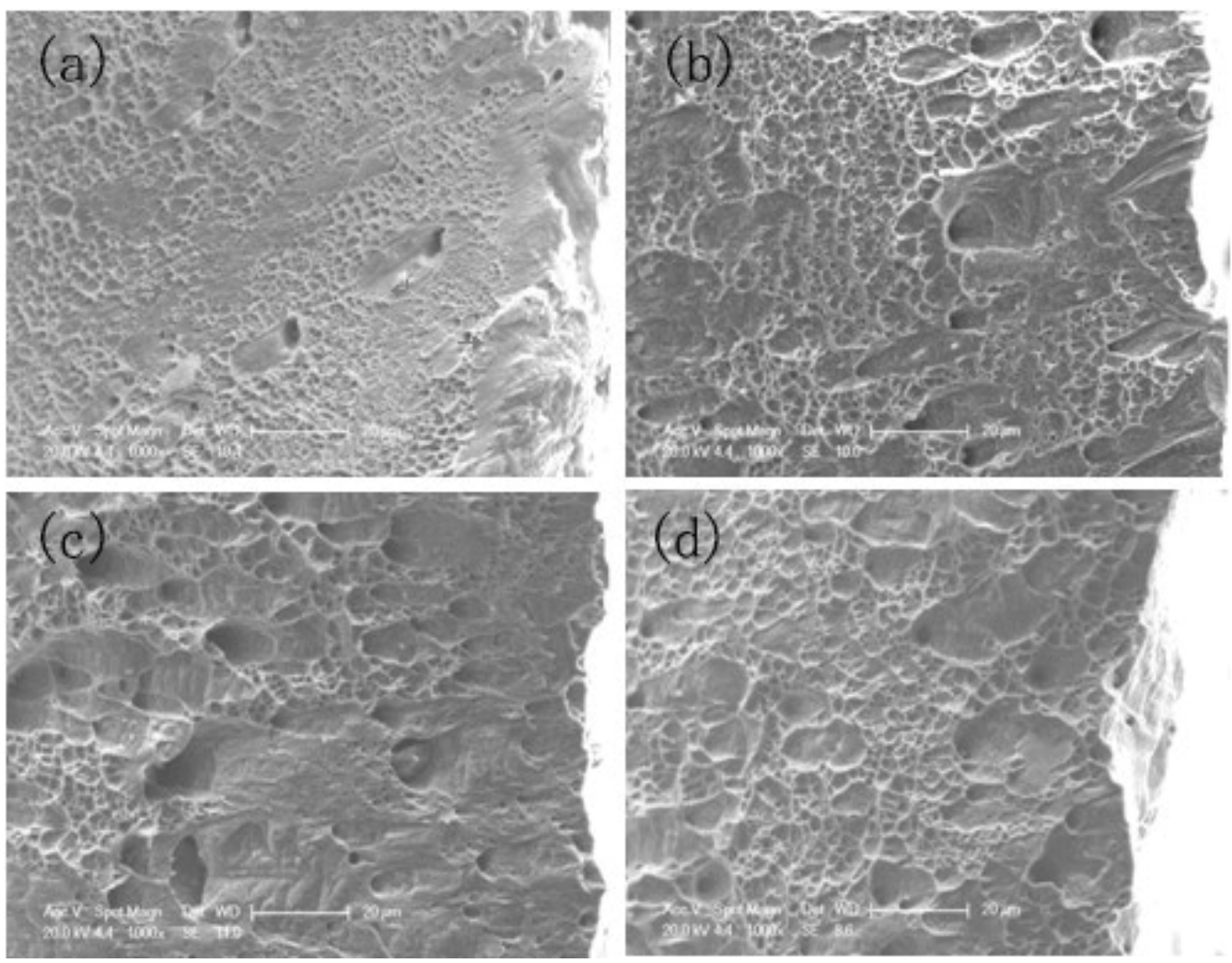

Figure 11: The SEM image of fractures a) $25^{\circ} \mathrm{C}$, b) $\left.100^{\circ} \mathrm{C}, \mathrm{c}\right) 200^{\circ} \mathrm{C}$, d) $300^{\circ} \mathrm{C}$ 
Figure 10 shows the macroscopic fracture morphology of tensile specimens which indicates that no significant necking occurs in all samples before fracture. Figure 11 are the SEM images of fractures at different tensile temperatures. The tensile specimens uniformly extend along their whole length and slightly shrink along width direction. Judging from SEM morphologies of tensile fracture, it is observed that a large number of dimples are distributed on tensile fracture and the fracture mechanism is ductile fracture. The diameter of fracture dimple increases with increasing temperature at the testing temperature range of $25^{\circ} \mathrm{C} \sim 200^{\circ} \mathrm{C}$, but the size of dimple is significantly reduced at $300^{\circ} \mathrm{C}$.

\section{Conclusions}

The yield strength, tensile strength and elongation of TWIP steel decrease with increasing test temperature. The microstructural changes suggested by the alterations in the tensile curves at elevated temperatures are confirmed by OM, SEM and TEM studies. Deformation twins gradually disappear with increased temperature which is according to the increased SFE. Deformation twinning has an important role in the plastic deformation due to its contribution to strain hardening and the delayed necking. Due to the increased temperature, the stacking fault energy becomes high enough to restrain twinning, thus dislocation glide will become the main deformation mechanism. The reduction of twins is responsible for the decrease of the strength and ductility of samples. Therefore, the deformation process cannot benefit from the deformation twins and the specimens fail earlier. Through observing and analyzing the phase and twin structure, the sample is a single austenite before and after deformation at different temperatures, and the width of deformation twin decreases as the temperature increases. The shear fracture morphologies by SEM show that the fracture mechanism of TWIP steel at testing temperature range of $25-300^{\circ} \mathrm{C}$ is ductile fracture.

Acknowledgement: Project No.: Science and Technology Project of Hebei Province, China under Grant No.16211005D.

\section{References}

[1] Xu, B. G. and T. Jia, Research and application of expandable pipe technology in Drilling. petroleum machinery, Vol. 41, no. 4, 2013, pp. 11-15.
[2] Yang, L. H., Development and performance analysis of TWIP steel for expandable screen shell. Doctoral Dissertation.Chengdu: Southwest Petroleum University, 2011.

[3] Graseel, O., G. Frommeyer, and C. Dercler. Phase transformation and mechanical Properties of Fe-Mn-Al-Si TRIP-Steel. Phys Iv France, Vol. C, C5, 1997, p. 178.

[4] Frommeyer, G., U. Brux, and P. Neumann. Supra-ductile and high strength manganese TRIP/TWIP steels for high energy absorption purpose. ISIJ International, Vol. 43, No. 3, 2003, pp. 438-446.

[5] Mi, Z. L., Research and development of a new generation of high strength and high plasticity TWIP steel for automobile. Doctoral Dissertation. Beijing: University of Science and Technology Beijing, 2007.

[6] Ma, M. Y., The study on organization of Fe-Mn-Al-Si TWIP steel. Doctoral Dissertation. Tangshan: Hebei United University, 2013.

[7] Lan, P., L. Song, C. Du, and J. Zhang. Analysis of solidification microstructure and hot ductility of Fe-22Mn-0.7C TWIP steel. Materials Science and Technology, Vol. 30, No. 11, 2014, pp. 1297-1304.

[8] Lan, P., C. Du, and Y. Ji. Research status of high manganese TWIP steel for automotive industry. China Metall., Vol. 24, No. 7, 2014, pp. 6-16.

[9] Zhu, H.-B., Material Properties Research and Application of Expandable Screen Base Pipe. Doctoral Dissertation. Chengdu: Southwest Petroleum University, 2012.

[10] Wang J.-T., The effect of chromium content on microstructure and mechanical property of Fe-Mn-Cr-C TWIP steel. Doctoral Dissertation. Fuzhou: Fuzhou University, 2016.

[11] Karaman, I., G. Yapici, Y. I. Chumlyakov, and I. V. Kireeva. Deformation Twinning in Diflcult-to-Work Alloys During Severe Plastic Deformation. Materials Science and Engineering A, Vol. 410-411, 2005, pp. 243-247.

[12] El-Danaf, E., S. R. Kalidindi, and R. D. Doherty. Influence of Grain Size and Stacking Fault Energy on Deformation Twinning in FCC Metals. Metallurgical and Materials Transactions. A, Physical Metallurgy and Materials Science, Vol. 30, No. 5, 1990, pp. 12231233.

[13] Asgari, S., E. El-Danaf, S. R. Kalidindi, and R. D. Doherty. Strain Hardening Regimes and Microstructural Evolution During Large Strain Compression of Low Stacking Fault Energy FCC Alloys That Form Deformation Twins. Metallurgical and Materials Transactions. A, Physical Metallurgy and Materials Science, Vol. 28, No. 9, 1997, pp. 1781-1795.

[14] Chao, H., and Y. Gang, Analysis of TWIP Effect. Iron \& Steel, Vol. 45, No. 8, 2010, pp. 70-74.

[15] Yang, S. L., and Y. J. Gu. Effect of deformation temperature on the mechanical properties and stacking fault energy of TWIP steel. Shanghai Metal, Vol. 38, No. 2, 2016, pp. 7-11.

[16] Shterner, V., A. Molotnikov, I. Timokhina, Y. Estrin, and H. Beladi. A constitutive model of the deformation behavior of twinning induced plasticity (TWIP) steel at different temperatures. Materials Science and Engineering A, Vol. 613, 2014, pp. 224-231.

[17] Lo, K. H., C. H. Shek, and J. Lai. Recent developments in stainless steels, Mater. Sci. Eng. RRep., Vol. 65, No. 4-6, 2009, pp. 39104.

[18] Li, J. G., Y. J. Ding, X. Peng, and J. Liu. Effect of water quenching process on the microstructure and mechanical properties of TWIP steel. Journal of Metals, Vol. 46, No. 2, 2010, pp. 221-226.

[19] Yang, J.-X., Physical Basis of Matal Plastic Deformation. Metallurgical Industury Press, Beijing, 1988, p. 185. 
[20] Molnára, D., X. Sun, and S. Lu. Effect of temperature on the stacking fault energy and deformation behavior in $316 \mathrm{~L}$ austenitic stainless steel. Materials Science and Engineering A, Vol. 759, 2019, pp. 490-497.

[21] Bronkhorst, C., S. Kalidindi, and L. Anand. Polycrystalline plasticity and the evolution of crystallographic texture in FCC metal. Phiklos T R Soc A, Vol. 1992, No. 341, 1662, pp. 443-477.

[22] Benzing, J. T., Y. Liu, X. Zhang, W. E. Luecke, D. Ponge, A. Dutta, C. Oskay, D. Raabe, and J. E. Wittig. Experimental and numerical study of mechanical properties of multi-phase medium-Mn TWIPTRIP steel: Influences of strain rate and phase constituents. Acta Materialia, Vol. 177, 2019, pp. 250-265.
[23] Sinha, S., J. A. Szpunar, N. K. Kumar, and N. Gurao. Tensile deformation of 3161 austenitic stainless steel using in-situ electron backscatter diffraction and crystal plasticity simulations. Materials Science and Engineering A, Vol. 637, 2015, pp. 48-55.

[24] Xiong, Y., T. He, Y. Lu, F. Ren, A. A. Volinsky, and W. Cao. Tensile deformation temperature impact on microstructure and mechanical properties of aisi $316 \mathrm{ln}$ austenitic stainless steel. Journal of Materials Engineering and Performance, Vol. 27, No. 3, 2018, pp. 1232-1240.

[25] Haasen, P., Physical Metallurgy. Beijing: Science Press, 1984. 